\title{
Antimicrobial Susceptibility Profiles of Staphylococcus aureus Isolates Recovered from Humans, Environmental Surfaces, and Companion Animals in Households of Children with Community-Onset Methicillin-Resistant $S$. aureus Infections
}

\author{
John J. Morelli, ${ }^{a}$ Patrick G. Hogan, ${ }^{a}$ Melanie L. Sullivan, ${ }^{a}$ Carol E. Muenks, ${ }^{a}$ Jeffrey W. Wang, ${ }^{a}$ Ryley M. Thompson, ${ }^{a}$ \\ (D) Carey-Ann D. Burnham, ${ }^{\text {a,b }}$ (D) Stephanie A. Fritz ${ }^{\mathbf{a}}$ \\ Departments of Pediatrics ${ }^{\mathrm{a}}$ and Pathology \& Immunology, Washington University School of Medicine, St. Louis, Missouri, USA
}

Our objective was to determine the antibiotic susceptibility profiles of Staphylococcus aureus isolates recovered from 110 households of children with community-onset methicillin-resistant S. aureus (MRSA) infections. Cultures were obtained from household members, household objects, and dogs and cats, yielding 1,633 S. aureus isolates. The S. aureus isolates were heterogeneous, although more than half were methicillin resistant. The highest proportion of MRSA was found in bathrooms. The majority of isolates were susceptible to antibiotics prescribed in outpatient settings.

A ntimicrobial-resistant bacterial infections are a global problem (1-3). Few studies have described the antimicrobial resistance profiles of Staphylococcus aureus strains in the community, specifically in household environments $(4,5)$. Household vectors, including humans, environmental fomites, and companion animals, may serve as reservoirs for methicillin-resistant $S$. aureus (MRSA) transmission (5-7). We describe here the antibiotic susceptibility patterns of $S$. aureus isolates recovered from these household vectors. Understanding the antibacterial resistance profiles of $S$. aureus strains in the environment may inform empirical antibiotic selection in clinical settings.

Following approval from the Washington University human and animal institutional review boards, pediatric patients $(n=$ 110) with community-onset MRSA infections and their household contacts $(n=388)$ were enrolled through St. Louis Children's Hospital (SLCH) and community pediatric practices from January 2013 to May 2014, as previously described (4). Study visits were conducted in the participants' homes, occurring up to 10 times over 24 months at 3-month intervals. During each visit, cultures were obtained from the axillae, anterior nares, and inguinal folds (ESwabs; Becton Dickinson, Franklin Lakes, NJ) from all consenting household members, up to 21 frequently touched standardized household objects (Table 1; ESwabs and BairdParker agar contact plates; Hardy, Santa Maria, CA) $(4,8)$, and the anterior nares and dorsal fur of indoor dogs and cats (BBL CultureSwab liquid Amies, regular aluminum wire; Becton Dickinson).

In accordance with Clinical and Laboratory Standards Institute (CLSI) guidelines for creating a cumulative antibiogram report (9), the first S. aureus isolate recovered from each pet, household object, or body site of each household member was included in the analysis. Antibiotic susceptibility testing (Table 1) of S. aureus isolates was performed by Kirby-Bauer disk diffusion (10, 11). High-level mupirocin resistance was confirmed by the detection of mupA (12). Isolates with intermediate susceptibility were categorized as resistant (11). MRSA isolates resistant to $\beta$-lactams plus three additional systemic antimicrobial classes (i.e., excluding mupirocin) were classified as multidrug resistant (MDR4) $(13,14)$.

Statistical analysis was conducted with SPSS 22 for Windows
(IBM SPSS, Chicago, IL). Isolate susceptibilities were compared between human, pet, and environmental isolates using the Fisher's exact or chi-square test. $P$ values of $<0.05$ were considered significant.

As summarized in Table 1, 1,633 unique $S$. aureus isolates were characterized, including 770 human isolates (47\%) (110 from sites of infection and 660 from sites of colonization), 815 environmental isolates (50\%), and 48 companion animal isolates (3\%) (39 from dogs and 9 from cats). Overall, $52 \%$ of the S. aureus isolates recovered from household environmental surfaces were methicillin resistant, as were $52 \%$ of the human colonization isolates (index patients and household contacts), and 63\% of the pet colonization isolates. All isolates were susceptible to trimethoprimsulfamethoxazole, linezolid, ceftaroline, and rifampin, while the majority of isolates were susceptible to clindamycin, tetracycline, and mupirocin (Table 1). Overall, multidrug resistance (MDR4) was low, comprising $4 \%$ of all recovered $S$. aureus isolates.

$S$. aureus isolates recovered from index patient infection cultures had a higher prevalence of erythromycin (83\%) and ciprofloxacin $(58 \%)$ resistance than that of isolates recovered from index patient colonization sites (54\%, $P<0.001$, and 33\%, $P<$ 0.001 , respectively). Index patient-infecting isolates trended to possess a higher prevalence of MDR4 than that of their colonizing isolates ( $9 \%$ versus $3 \%, P=0.07$ ). There were no significant dif-

Received 25 June 2015 Returned for modification 15 July 2015

Accepted 20 July 2015

Accepted manuscript posted online 27 July 2015

Citation Morelli JJ, Hogan PG, Sullivan ML, Muenks CE, Wang JW, Thompson RM, Burnham C-AD, Fritz SA. 2015. Antimicrobial susceptibility profiles of

Staphylococcus aureus isolates recovered from humans, environmental surfaces, and companion animals in households of children with community-onset methicillin-resistant S. aureus infections. Antimicrob Agents Chemother 59:6634-6637. doi:10.1128/AAC.01492-15

Address correspondence to Stephanie A. Fritz, fritz_s@kids.wustl.edu.

J.J.M. and P.G.H. contributed equally to this work.

Copyright @ 2015, American Society for Microbiology. All Rights Reserved. doi:10.1128/AAC.01492-15 
TABLE 1 Antimicrobial susceptibility profiles of S. aureus isolates recovered from households of children with community-onset MRSA infection

\begin{tabular}{|c|c|c|c|c|c|c|c|c|c|c|c|c|}
\hline \multirow[b]{2}{*}{ Location from which isolate was recovered } & \multirow{2}{*}{$\begin{array}{l}\text { No. of } S \text {. aureus } \\
\text { isolates tested }\end{array}$} & \multicolumn{10}{|c|}{$\%$ susceptible ${ }^{a}$} & \multirow{2}{*}{$\begin{array}{l}\% \\
\mathrm{MDR}^{d}\end{array}$} \\
\hline & & $\mathrm{MET}^{b}$ & $\mathrm{CLI}^{c}$ & ERY & SXT & RIF & TET & CIP & LZD & $\mathrm{CPT}$ & MUP & \\
\hline Overall & 1,633 & 45 & 90 & 47 & 100 & 100 & 98 & 68 & 100 & 100 & 96 & 4 \\
\hline Index patient & 263 & 26 & 91 & 34 & 100 & 100 & 99 & 58 & 100 & 100 & 95 & 5 \\
\hline Infection & $110^{e}$ & $0^{f}$ & 94 & 17 & 100 & 100 & 99 & 42 & 100 & 100 & 98 & 9 \\
\hline Colonization & 153 & 44 & 89 & 46 & 100 & 100 & 99 & 67 & 100 & 100 & 94 & 3 \\
\hline Inguinal folds & 61 & 41 & 89 & 39 & 100 & 100 & 98 & 69 & 100 & 100 & 95 & 3 \\
\hline Household contact colonization $^{g}$ & 507 & 50 & 89 & 49 & 100 & 100 & 98 & 68 & 100 & 100 & 96 & 4 \\
\hline Anterior nares & 228 & 55 & 90 & 52 & 100 & 100 & 99 & 69 & 100 & 100 & 97 & 4 \\
\hline Axillae & 110 & 44 & 90 & 46 & 100 & 100 & 99 & 69 & 100 & 100 & 95 & 5 \\
\hline Inguinal folds & 169 & 47 & 88 & 47 & 100 & 100 & 96 & 67 & 100 & 100 & 95 & 4 \\
\hline Adult household contact colonization & 278 & 49 & 88 & 45 & 100 & 100 & 97 & 67 & 100 & 100 & 95 & 4 \\
\hline Axillae & 48 & 46 & 90 & 52 & 100 & 100 & 100 & 67 & 100 & 100 & 94 & 6 \\
\hline Inguinal folds & 73 & 48 & 92 & 52 & 100 & 100 & 99 & 73 & 100 & 100 & 97 & 3 \\
\hline Pets & 48 & 38 & 85 & 48 & 100 & 100 & 100 & 69 & 100 & 100 & 96 & 8 \\
\hline Dog & 39 & 41 & 87 & 56 & 100 & 100 & 100 & 74 & 100 & 100 & 100 & 8 \\
\hline Anterior nares & 16 & 38 & 88 & 69 & 100 & 100 & 100 & 81 & 100 & 100 & 100 & 6 \\
\hline Dorsal fur & 23 & 44 & 87 & 48 & 100 & 100 & 100 & 70 & 100 & 100 & 100 & 9 \\
\hline Cat & 9 & 22 & 78 & 11 & 100 & 100 & 100 & 44 & 100 & 100 & 78 & 11 \\
\hline Anterior nares & 4 & 25 & 75 & 25 & 100 & 100 & 100 & 25 & 100 & 100 & 75 & 25 \\
\hline Dorsal fur & 5 & 20 & 80 & 0 & 100 & 100 & 100 & 60 & 100 & 100 & 80 & 0 \\
\hline Environment & 815 & 48 & 90 & 50 & 100 & 100 & 98 & 71 & 100 & 100 & 97 & 3 \\
\hline Living room & 166 & 44 & 88 & 52 & 100 & 100 & 99 & 69 & 100 & 100 & 97 & 4 \\
\hline TV remote control & 52 & 42 & 90 & 44 & 100 & 100 & 98 & 67 & 100 & 100 & 96 & 4 \\
\hline Door handle & 32 & 47 & 91 & 41 & 100 & 100 & 100 & 63 & 100 & 100 & 97 & 0 \\
\hline Light switch & 39 & 49 & 92 & 49 & 100 & 100 & 100 & 64 & 100 & 100 & 100 & 5 \\
\hline Sink & 52 & 48 & 94 & 54 & 100 & 100 & 100 & 75 & 100 & 100 & 98 & 0 \\
\hline Bathtub or shower & 44 & 50 & 89 & 46 & 100 & 100 & 96 & 82 & 100 & 100 & 98 & 2 \\
\hline Soap bar or dish in bathtub or shower & 17 & 29 & 82 & 29 & 100 & 100 & 88 & 65 & 100 & 100 & 100 & 6 \\
\hline Toilet seat & 47 & 60 & 89 & 55 & 100 & 100 & 98 & 81 & 100 & 100 & 100 & 0 \\
\hline Countertop & 48 & 48 & 92 & 46 & 100 & 100 & 96 & 70 & 100 & 100 & 96 & 2 \\
\hline Kitchen & 190 & 49 & 91 & 52 & 100 & 100 & 99 & 71 & 100 & 100 & 95 & 3 \\
\hline Hand towel & 22 & 55 & 91 & 50 & 100 & 100 & 100 & 68 & 100 & 100 & 96 & 0 \\
\hline Sink faucet handle & 35 & 46 & 97 & 60 & 100 & 100 & 100 & 66 & 100 & 100 & 94 & 3 \\
\hline Sponge/cloth & 32 & 47 & 94 & 59 & 100 & 100 & 100 & 75 & 100 & 100 & 94 & 3 \\
\hline Refrigerator door handle & 55 & 47 & 86 & 49 & 100 & 100 & 100 & 71 & 100 & 100 & 95 & 6 \\
\hline Kitchen table & 46 & 52 & 91 & 44 & 100 & 100 & 98 & 74 & 100 & 100 & 96 & 0 \\
\hline Bedroom & 55 & 40 & 89 & 46 & 100 & 100 & 98 & 64 & 100 & 100 & 95 & 4 \\
\hline Bed sheets and pillowcase & 55 & 40 & 89 & 46 & 100 & 100 & 98 & 64 & 100 & 100 & 95 & 4 \\
\hline
\end{tabular}

${ }^{a}$ MET, methicillin; CLI, clindamycin; ERY, erythromycin; SXT, trimethoprim-sulfamethoxazole; RIF, rifampin; TET, tetracycline; CIP, ciprofloxacin; LZD, linezolid; CPT, ceftaroline; MUP, mupirocin.

${ }^{b}$ As predicted by cefoxitin testing.

${ }^{c}$ Clindamycin-susceptible isolates exhibiting inducible clindamycin resistance $(n=144)$ were considered clindamycin resistant.

${ }^{d}$ Multidrug resistance (MDR4) here was defined as $\beta$-lactam resistance plus resistance to three additional systemic antimicrobial drug classes (i.e., excluding mupirocin),

${ }^{e}$ Some infection isolates were unable to be obtained by the study team and are thus missing various susceptibility data; therefore, $\%$ susceptibility is out of $<110$ for RIF $(n=84)$,

CIP $(n=85)$, LZD $(n=76)$, CPT $(n=64)$, and MUP $(n=64)$

${ }^{f}$ Study entry criteria specified a MRSA infection.

${ }^{g}$ Does not include the isolates recovered from index patients. 
ferences in antibiotic susceptibility between colonizing isolates recovered from index patients and those from household contacts.

The household environmental surfaces with the highest prevalence of MRSA isolates were the soap bar/dish in the bathtub/ shower $(71 \%)$, bathroom hand towel $(68 \%)$, and telephone (64\%). MDR4 isolates were most commonly recovered from the soap bar/dish in the bathtub/shower $(6 \%)$, refrigerator door handle $(6 \%)$, computer keyboard/mouse (5\%), and bathroom light switch $(5 \%)$. There were no significant differences in antibiotic susceptibilities in a comparison of isolates recovered from different areas of the home, e.g., the living room, bathroom, kitchen, and bedroom.

The overall number of $S$. aureus isolates recovered from pets was relatively small $(n=48)$, although these isolates were most frequently methicillin resistant (63\%) compared to isolates recovered from human $(58 \%)$ or environmental sources $(52 \% ; P=$ $0.03)$. Companion animal isolates also had the highest prevalence of MDR4 (8\%) compared to that of human (4\%) or environmental isolates $(3 \% ; P=0.04)$. Resistance to erythromycin and mupirocin was higher in isolates recovered from cats than that in dogs (89\% versus $44 \%, P=0.02$, and $22 \%$ versus $0 \%, P=0.03$, respectively).

In this study of antimicrobial susceptibility patterns of $S$. aureus isolated from household vectors, more than half of the recovered isolates were MRSA; of note, the majority of isolates were susceptible to systemic antibiotics commonly prescribed for $S$. aureus infections in outpatient settings (15) and were universally susceptible to the newer antimicrobials linezolid and ceftaroline $(16,17)$. Interestingly, $5 \%$ of the isolates recovered from index patients were mupirocin resistant, which is higher than findings of a prior study by our group conducted from 2007 to 2009, in which $2 \%(50$ of 2,425$)$ of the $S$. aureus isolates collected from a similar patient population were mupirocin resistant (12).

Environmental surfaces may serve as reservoirs for MRSA transmission within households. In this study, the soap bar/dish, bathroom hand towel, and telephone possessed the highest prevalence of MRSA. Additionally, MDR4 strains were commonly recovered from the refrigerator door handle, computer keyboard/ mouse, and bathroom light switch. Similar to other studies, these findings may reflect the high frequency of contact with these surfaces by a variety of household members, compared to surfaces likely to be unique to the index patient (e.g., bed linens or bath towels) $(5,18)$. In our population, a high proportion of strains recovered from pet dogs and cats were MRSA, consistent with a notable increase in the prevalence of antibioticresistant staphylococcal strains in companion animals over the past decade $(19,20)$.

The present study analyzed a broad range of antimicrobial susceptibility profiles of $S$. aureus isolates from households of children with MRSA infections. The strengths of this study include the large number of isolates collected and the breadth, standardization, and longitudinal sampling of humans, household environments, and companion animals. Although the isolates are from a single metropolitan area, the households represent a diverse geographic (121-mi diameter) and sociodemographic catchment. A limitation is that several sampled sites (cats and various environmental surfaces) did not provide the minimum number $(n=30)$ of isolates necessary to audit an antibiogram profile (11), which may provide a limited picture of antimicrobial trends.

In conclusion, we observed a heterogeneous population of $S$. aureus isolates in households of children with MRSA infections. As personal S. aureus colonization and the colonization of household contacts and environmental surfaces are putative reservoirs for subsequent infection, we are encouraged by the fact that the majority of isolates were susceptible to commonly prescribed antibiotics used for community-onset $S$. aureus infection.

\section{ACKNOWLEDGMENTS}

We thank Meghan Wallace for contributing her technical expertise. We thank Rachel Orscheln, Lisa Robertson, Mary Boyle, Madeline Martin, Jennifer Seigel, and the SLCH pediatric ambulatory wound service for their assistance in patient recruitment and Jane Garbutt and the physicians and staff of the participating Washington University Pediatric and Adolescent Ambulatory Research Consortium practices, including Mercy Pediatrics-Union and Washington, Johnson Pediatric Center, Heartland Pediatrics, Forest Park Pediatrics, Tots Through Teens, Pediatric Healthcare Unlimited, Northwest Pediatrics-St. Charles, Fenton Pediatrics, LLC, and Southwest Pediatrics. We thank the SLCH clinical microbiology laboratory technologists for procuring clinical isolates from the participants. We also thank Michael Talcott and Mary Ellenberger for providing training in animal culturing and Victoria Fraser and Sarah Gehlert for assistance with study design. These individuals and entities did not receive compensation (financial or otherwise) for their contributions.

Funding for this project was provided by the Children's Discovery Institute of Washington University and St. Louis Children's Hospital, National Institutes of Health grants K23-AI091690, KL2-RR024994, and UL1-TR000448, and grant R01-HS021736 from the Agency for Healthcare Research and Quality.

The content of this article is solely the responsibility of the authors and does not necessarily represent the official views of the National Institutes of Health or the Agency for Healthcare Research and Quality.

\section{REFERENCES}

1. Barbosa TM, Levy SB. 2000. The impact of antibiotic use on resistance development and persistence. Drug Resist Updat 3:303-311. http://dx.doi .org/10.1054/drup.2000.0167.

2. Rodríguez-Rojas A, Rodríguez-Beltrán J, Couce A, Blázquez J. 2013. Antibiotics and antibiotic resistance: a bitter fight against evolution. Int J Med Microbiol 303:293-297. http://dx.doi.org/10.1016/j.ijmm.2013.02 .004 .

3. Centers for Disease Control and Prevention. 2013. Antibiotic resistance threats in the United States. Centers for Disease Control and Prevention, Atlanta, GA. http://www.cdc.gov/drugresistance/pdf/ar-threats-2013-508 .pdf.

4. Fritz SA, Hogan PG, Singh LN, Thompson RM, Wallace MA, Whitney K, Al-Zubeidi D, Burnham CA, Fraser VJ. 2014. Contamination of environmental surfaces with Staphylococcus aureus in households with children infected with methicillin-resistant $S$ aureus. JAMA Pediatr 168: 1030-1038. http://dx.doi.org/10.1001/jamapediatrics.2014.1218.

5. Uhlemann AC, Knox J, Miller M, Hafer C, Vasquez G, Ryan M, Vavagiakis P, Shi Q, Lowy FD. 2011. The environment as an unrecognized reservoir for community-associated methicillin resistant Staphylococcus aureus USA300: a case-control study. PLoS One 6:e22407. http://dx .doi.org/10.1371/journal.pone.0022407.

6. Davis MF, Iverson SA, Baron P, Vasse A, Silbergeld EK, Lautenbach E, Morris DO. 2012. Household transmission of meticillin-resistant Staphylococcus aureus and other staphylococci. Lancet Infect Dis 12:703-716. http://dx.doi.org/10.1016/S1473-3099(12)70156-1.

7. Miller LG, Diep BA. 2008. Clinical practice: colonization, fomites, and virulence: rethinking the pathogenesis of community-associated methicillin-resistant Staphylococcus aureus infection. Clin Infect Dis 46:752-760. http://dx.doi.org/10.1086/526773.

8. Hogan PG, Burnham C-AD, Singh LN, Patrick CE, Lukas JC, Wang JW, Fraser VJ, Fritz SA. 2015. Evaluation of environmental sampling methods for detection of Staphylococcus aureus on fomites. Ann Public Health Res 2:1013.

9. Clinical and Laboratory Standards Institute. 2014. Analysis and presentation of cumulative antimicrobial susceptibility test data, 4th ed. CLSI document M39-A4. Clinical and Laboratory Standards Institute, Wayne, PA. 
10. Clinical and Laboratory Standards Institute. 2013. Performance standards for antimicrobial susceptibility testing; 23rd informational supplement. CLSI document M100-S23. Clinical and Laboratory Standards Institute, Wayne, PA.

11. Lewis JS, Jr, Jorgensen JH. 2005. Inducible clindamycin resistance in staphylococci: should clinicians and microbiologists be concerned? Clin Infect Dis 40:280-285. http://dx.doi.org/10.1086/426894.

12. Fritz SA, Hogan PG, Camins BC, Ainsworth AJ, Patrick C, Martin MS, Krauss MJ, Rodriguez M, Burnham CA. 2013. Mupirocin and chlorhexidine resistance in Staphylococcus aureus in patients with community-onset skin and soft tissue infections. Antimicrob Agents Chemother 57:559568. http://dx.doi.org/10.1128/AAC.01633-12.

13. Davis MF, Peterson AE, Julian KG, Greene WH, Price LB, Nelson K, Whitener CJ, Silbergeld EK. 2013. Household risk factors for colonization with multidrug-resistant Staphylococcus aureus isolates. PLoS One 8:e54733. http://dx.doi.org/10.1371/journal.pone.0054733.

14. Moet GJ, Jones RN, Biedenbach DJ, Stilwell MG, Fritsche TR. 2007. Contemporary causes of skin and soft tissue infections in North America, Latin America, and Europe: report from the SENTRY Antimicrobial Surveillance Program (1998-2004). Diagn Microbiol Infect Dis 57:7-13. http://dx.doi.org/10.1016/j.diagmicrobio.2006.05.009.

15. Liu C, Bayer A, Cosgrove SE, Daum RS, Fridkin SK, Gorwitz RJ, Kaplan SL, Karchmer AW, Levine DP, Murray BE, JR M, Talan DA, Chambers HF, Infectious Diseases Society of America. 2011. Clinical practice guidelines by the Infectious Diseases Society of America for the treatment of methicillin-resistant Staphylococcus aureus infections in adults and chil- dren: executive summary. Clin Infect Dis 52:285-292. http://dx.doi.org /10.1093/cid/cir034.

16. File TM, Jr, Wilcox MH, Stein GE. 2012. Summary of ceftaroline fosamil clinical trial studies and clinical safety. Clin Infect Dis 55(Suppl 3):S173S180. http://dx.doi.org/10.1093/cid/cis559.

17. Richter SS, Diekema DJ, Heilmann KP, Dohrn CL, Crispell EK, Riahi F, McDanel JS, Satola SW, Doern GV. 2014. Activities of vancomycin, ceftaroline, and mupirocin against Staphylococcus aureus isolates collected in a 2011 national surveillance study in the United States. Antimicrob Agents Chemother 58:740-745. http://dx.doi.org/10.1128/AAC.01915-13.

18. Eells SJ, David MZ, Taylor A, Ortiz N, Kumar N, Sieth J, Boyle-Vavra S, Daum RS, Miller LG. 2014. Persistent environmental contamination with USA300 methicillin-resistant Staphylococcus aureus and other pathogenic strain types in households with S. aureus skin infections. Infect Control Hosp Epidemiol 35:1373-1382. http://dx.doi.org/10.1086/678414.

19. Wedley AL, Dawson S, Maddox TW, Coyne KP, Pinchbeck GL, Clegg P, Jamrozy D, Fielder MD, Donovan D, Nuttall T, Williams NJ. 2014. Carriage of Staphylococcus species in the veterinary visiting dog population in mainland UK: molecular characterisation of resistance and virulence. Vet Microbiol 170:81-88. http://dx.doi.org/10.1016/j.vetmic.2014 .01 .015 .

20. Rubin JE, Chirino-Trejo M. 2011. Antimicrobial susceptibility of canine and human Staphylococcus aureus collected in Saskatoon, Canada. Zoonoses Public Health 58:454-462. http://dx.doi.org/10.1111/j.1863-2378 .2011.01392.x. 